\title{
Lipid profile in pre-dialysis chronic kidney disease patients in southern Nige- ria
}

\author{
Oluseyi A. Adejumo ${ }^{1}$, Enajite I. Okaka ${ }^{2}$ and Louis I. Ojogwu ${ }^{2}$ \\ ${ }^{1}$ Kidney Care Centre, University of Medical Sciences, Ondo, Ondo State, Nigeria ${ }^{2}$ Department of Internal \\ Medicine, University of Benin Teaching Hospital, Benin, Benin City, Edo State, Nigeria.
}

DOI: $h t t p: / / d x$. doi.org/10.4314/gmj.v50i1.7

Corresponding author: Dr Oluseyi A. Adejumo？ E-mail: ceeward2010@yahoo.com

Conflict of interest: None declared

\section{SUMMARY}

Background: Dyslipidaemia is one of the cardiovascular risk factors responsible for cardiovascular disease and rapid progression of chronic kidney disease (CKD) to end stage renal disease. Early detection and management of dyslipidaemia will reduce cardiovascular burden and retard progression of CKD.

Aims: To determine the prevalence and pattern of dyslipidaemia in pre-dialysis CKD patients in a tertiary hospital in southern Nigeria.

Methods: This was a case-control study that involved 105 consecutive pre-dialysis CKD patients recruited over two years and 105 age and sex matched control subjects. Data obtained from participants included demographics, body mass index, and aetiology of CKD. Blood sampling was done for the determination of creatinine and fasting serum lipids. $\mathrm{P}$ values $<0.05$ were taken as significant.

Results: The mean age of the CKD and control subjects were $46.98 \pm 16.81$ and $47.57 \pm 15.97$ years respectively with a male:female ratio of 1.7:1. The median atherogenic index of plasma (AIP), low density lipoprotein-cholesterol and triglyceride (TG) were significantly higher in the CKD patients while mean high density lipoprotein-cholesterol (HDL-C) was significantly lower in the CKD patients $(\mathrm{p}=<0.001)$. The overall prevalence of dyslipidaemia in the CKD patients was $60 \%$ which was significantly higher than $39 \%$ in the control $(p=0.002)$. The prevalence of high AIP, elevated TG and reduced HDL-C increased with worsening renal function. Dyslipidaemia was commoner in female CKD patients $(\mathrm{p}=0.02)$ and those who were $\geq 45$ years $(\mathrm{p}=0.94)$.

Conclusion: Dyslipidaemia is common in pre-dialysis CKD especially in female and older patients. Some lipid abnormalities increased with worsening kidney function.

Keywords: dyslipidaemia, pre-dialysis, chronic kidney disease, Nigeria

\section{INTRODUCTION}

Cardiovascular disease is the leading cause of hospitalization and mortality in patients with chronic kidney disease. ${ }^{1}$ The process of cardiovascular disease most likely started in early stages of CKD considering its severity at commencement of renal replacement therapy (RRT). ${ }^{2}$ Dyslipidaemia is one of the recognized traditional cardiovascular risk factors in the general population as well as CKD patients., ${ }^{3,4}$ This cardiovascular risk factor occurs commonly in patients with CKD. ${ }^{5-7}$

Dyslipidaemia is associated with rapid decline in renal function and commencement of RRT in CKD patients. ${ }^{8,9}$ The precise mechanism is unknown, but it has been postulated that mesangial cells bind and take up oxidized LDL which then causes injury to mesangial, epithelial and endothelial cells by favouring recruitment of inflammatory cells such as macrophages which release cytokines, chemokines and growth factors. ${ }^{10,11}$
This subsequently leads to glomerulosclerosis. ${ }^{10}$ Hypercholesterolaemia and hypertriglyceridaemia also cause podocyte injury and mesangial sclerosis, subsequently leading to glomerulosclerosis.

Dyslipidaemia in CKD patients is characterized by elevated triglyceride (TG), elevated total cholesterol (TC), high density lipoprotein cholesterol (LDL-C) and reduced high density lipoprotein cholesterol (HDL-C) ${ }^{5-7}$ However, total cholesterol may be normal or reduced especially in the presence of malnutrition. The pattern of dyslipidaemia seen in CKD patients is highly atherogenic and is associated with development of atherosclerotic cardiovascular disease and all cause mortality. ${ }^{12}$

Dyslipidaemia is a modifiable cardiovascular risk factor, hence early diagnosis and management with both lifestyle modification and lipid lowering medications 
will reduce cardiovascular disease risk and progression to end stage renal disease (ESRD). Treatment of dyslipidaemia using statins has been reported to reduce the rate of decline in glomerular filtration rate (GFR) in CKD patients. ${ }^{13}$

We set out to determine the prevalence and pattern of dyslipidaemia in relation to age, gender and severity of CKD among pre-dialysis CKD patients attending a teaching hospital in Southern Nigeria.

\section{METHODS}

\section{Study Location}

The Renal unit, Department of Internal Medicine of University of Benin Teaching Hospital receives referral from within and outside the state of location. Renal clinic is run thrice weekly on consultant out-patients basis where an average of 10 newly diagnosed CKD patients are seen in the unit monthly.

\section{Study Design}

This was a case control study spanning over a 2-year period (September 2011 to August 2013) that involved 105 consecutive pre-dialysis CKD patients that fulfilled criteria for the study and 105 age and sex matched controls. Sample size was derived using the Fleiss formula for case-control study using the following information: 14

Confidence interval $=95 \%$, power of study $=80 \%$, ratio of cases to control of $1: 1$, percentage of control exposed: $8.7 \%{ }^{15}$ and percentage of cases exposed: $26 \%{ }^{5}$ (both were gotten from previous studies on dyslipidaemia in subjects with normal renal function and CKD respectively). This formula gave a minimum sample size of 75 for cases and 75 for control.

Inclusion criteria for CKD subjects were: adults aged $\geq$ 18 years, patients with CKD stages 1-5 yet to commence dialysis. CKD patients who were pregnant, already on dialysis, those who had renal transplant and those on dietary restriction (lipid lowering diet), lipid lowering medications, steroids or immunosuppressant were excluded from the study. Inclusion criteria for control subjects were adults aged $\geq 18$ years who were not hypertensive nor diabetic with normal renal function, females who were not pregnant and not on steroids, immunosuppressant or lipid lowering medications.

Demographic information including age and sex of participants were obtained. Patients were interviewed, examined and aetiologies of renal disease were determined. Weight was measured using a weighing scale made by U-MEC (model 98114) with subjects wearing light clothing.

The weighing scale was calibrated with known weights at the beginning of each clinic session and it was ensured that the scale was zeroed before measurements were taken in order to ensure accuracy of measurements. Height was measured using a stadiometer to the nearest centimeter with subjects neither wearing shoes nor head gear. Body mass index $\left(\mathrm{kg} / \mathrm{m}^{2}\right)$ was calculated using the formula Weight $(\mathrm{kg}) / \operatorname{Height}^{2}(\mathrm{~m})^{2}$.

About 10mls of fasting venous blood was obtained from patients to perform biochemical tests which included serum creatinine and fasting serum lipids. Total serum cholesterol and triglycerides were determined by enzymatic estimation, ${ }^{16}$ while HDL-C was determined by precipitation. ${ }^{17}$ LDL-C was estimated using Friedwald formula. ${ }^{18}$ Glomerular filtration rate was estimated using the Cockcroft Gault formula which has been previously validated in Nigerian subjects. ${ }^{19}$

\section{Definition of variables}

Obesity was defined as BMI $>29.9 \mathrm{~kg} / \mathrm{m}^{2} .{ }^{20}$ CKD stage 1 (GFR $\geq 90 \mathrm{mls} / \mathrm{min}$ with evidence of kidney damage), stage 2 (GFR 60-89 $\mathrm{mls} / \mathrm{min}$ with evidence of kidney damage), stage $3(\mathrm{GFR}=30-59 \mathrm{mls} / \mathrm{min}$ with or without evidence of kidney damage), stage 4 (GFR $=15$ $29 \mathrm{mls} / \mathrm{min}$ with or without evidence of kidney damage) and stage 5 (GFR $<15 \mathrm{mls} / \mathrm{min}$ with or without evidence of kidney damage). ${ }^{21}$ Dyslipidaemia was defined as any or a combination of the following: TC > $200 \mathrm{mg} / \mathrm{dl}$, HDL-C $<50 \mathrm{mg} / \mathrm{dl}$ in females and $<40$ $\mathrm{mg} / \mathrm{dl}$ in males, LDL-C $>135 \mathrm{mg} / \mathrm{dl}$ and $\mathrm{TG}>$ $150 \mathrm{mg} / \mathrm{dl}^{22}$ Atherogenic index of plasma (AIP) $>0.24$ was regarded as high cardiovascular risk. ${ }^{23}$

Ethical approval was obtained from the hospital ethics committee on research and informed consent was obtained from participants.

\section{Data Analysis}

Data generated were analyzed using the statistical package for social sciences (SPSS) version 17.0. Results were presented in tabular forms. Univariate analysis was used in description of demographic characteristics of the study population. Continuous variables were presented as mean and standard deviation for unskewed data and median, interquartile range for skewed data.

Student t-test was used to compare mean values of the sub-groups for those with unskewed data while Mann Whitney U test was used to compare skewed data. Discrete variables were presented as frequency and percentages. Chi-square test was used to determine the significance of observed differences for categorical varia- 
bles while chi-square with trend was used where the categorical variable was ordinal. $\mathrm{P}$ values $<0.05$ were considered significant.

\section{RESULTS}

This study involved 105 CKD patients and 105 age and sex matched control subjects. Each group comprised of 66 males and 39 females. About $48 \%$ of the CKD subjects were below 45 years. Chronic glomerulonephritis, hypertension and diabetes mellitus were the major aetiology of renal disease, accounting for $33.3 \%, 32.4 \%$ and $29.5 \%$ respectively. Most of these patients were in CKD stages 3 and 4 , accounting for $68.6 \%$ of the patients. (Table 1)

Table 1 Characteristics of study subjects

\begin{tabular}{|c|c|c|}
\hline & $\begin{array}{l}\text { CKD subjects } \\
(\mathrm{N}=105)\end{array}$ & $\begin{array}{l}\text { Control subjects } \\
(\mathrm{N}=105)\end{array}$ \\
\hline Parameter & n (\%) & n (\%) \\
\hline \multicolumn{3}{|l|}{ Gender } \\
\hline Male & $66(62.9)$ & $66(62.9)$ \\
\hline Female & $39(37.1)$ & $39(37.1)$ \\
\hline \multicolumn{3}{|l|}{ Age } \\
\hline$<45$ years & $47(47.8)$ & $47(47.8)$ \\
\hline$\geq 45$ years & $58(52.2)$ & $58(52.2)$ \\
\hline \multicolumn{3}{|l|}{ Diagnosis } \\
\hline $\begin{array}{l}\text { Chronic glo- } \\
\text { merulonephritis }\end{array}$ & $35(33.3)$ & \\
\hline $\begin{array}{l}\text { Hypertensive } \\
\text { nephropathy }\end{array}$ & $34(32.4)$ & \\
\hline $\begin{array}{l}\text { Diabetic } \\
\text { nephropathy }\end{array}$ & $31(29.5)$ & \\
\hline Others & $5(4.8)$ & \\
\hline \multicolumn{3}{|l|}{ CKD stages } \\
\hline 1 & $7(6.7)$ & \\
\hline 2 & $22(21.0)$ & \\
\hline 3 & $46(43.8)$ & \\
\hline 4 & $26(24.8)$ & \\
\hline 5 & $4 \quad(3.8)$ & \\
\hline
\end{tabular}

Table 2 shows a comparison of characteristics of the CKD and control groups. The mean age of the CKD and the control groups were $46.98 \pm 16.81$ years and $47.57 \pm 15.97$ years respectively with no significant difference $(p=0.794)$. There was no significant difference in the mean serum TC between the CKD and control groups.

The mean HDL-C and BMI were significantly lower in the CKD patients with $p$ values of $<0.001$ and 0.02 respectively. The median serum creatinine, TG, LDL-C and AIP were significantly higher in the CKD group compared with the control group with $\mathrm{p}$ values of $<0.001$.

Table 2: Comparison of parameters between the CKD and control groups

\begin{tabular}{|c|c|c|c|}
\hline Parameters & $\begin{array}{l}\text { CKD }(n=105) \\
\text { Mean } \pm \text { Sd }\end{array}$ & $\begin{array}{l}\text { Controls }(\mathrm{n}=105) \\
\text { Mean } \pm \text { Sd }\end{array}$ & $\mathrm{P}$ value \\
\hline Age (years) & $46.98 \pm 16.81$ & $47.57 \pm 15.97$ & 0.794 \\
\hline BMI $\left(\mathrm{kg} / \mathrm{m}^{2}\right)$ & $24.49 \pm 4.18$ & $26.03 \pm 5.00$ & 0.02 \\
\hline Serum TC (mg/dl) & $182.34 \pm 45.01$ & $178.95 \pm 53.91$ & 0.621 \\
\hline Serum $\mathrm{TG} \dagger(\mathrm{mg} / \mathrm{dl})$ & $105(60)$ & $72(59)$ & $<0.001$ \\
\hline Serum HDL-C(mg/dl) & $53.60 \pm 20.91$ & $74.51 \pm 24.23$ & $<0.001$ \\
\hline Serum LDL-C $\dagger(\mathrm{mg} / \mathrm{dl})$ & $101(214)$ & $85(70)$ & $<0.001$ \\
\hline $\begin{array}{l}\text { Atherogenic index of } \\
\text { Plasma } \dagger\end{array}$ & $0.34(0.32)$ & $0.01(0.48)$ & $<0.001$ \\
\hline $\begin{array}{l}\text { Serum } \\
\text { nine } \dagger(\mathrm{mg} / \mathrm{dl})\end{array}$ & $2.90(2.30)$ & $0.70(0.40)$ & $<0.001$ \\
\hline $\begin{array}{l}\dagger \text { Skewed data expresse } \\
\text { used. IQR (Interquartile } \\
\text { TG(triglyceride), LDL-C } \\
\text { C (high density lipoprote }\end{array}$ & $\begin{array}{l}\text { n Median(IQR } \\
\text { ge),TC(total ch } \\
\text { ow density lip } \\
\text { cholesterol) }\end{array}$ & $\begin{array}{l}\text { nd Man Whitney } \\
\text { sterol), } \\
\text { otein-cholesterol), }\end{array}$ & test \\
\hline
\end{tabular}

The prevalence of lipid abnormalities present in CKD versus control subjects were; elevated TC $(29.5 \%$ vs $29.5 \%)$, elevated TG $(19.0 \%$ vs $13.3 \%)$, elevated LDLC (16.2\% vs $15.2 \%)$, low HDL-C (30.5\% vs $7.6 \%)$, high AIP (64.8\% vs 33.8\%). The prevalence of reduced serum HDL-C, high AIP and dyslipidaemia were significantly higher in the CKD groups compared to the control with $\mathrm{p}$ values of $<0.001,<0.001$ and 0.002 respectively. There was no significant difference between the prevalence of elevated serum TC, TG and LDL-C in both groups. The overall prevalence of dyslipidaemia was $60.0 \%$ in the CKD patients which was significantly higher than $39 \%$ present in the control subjects. (Table 3)

Table 3 Comparison of Lipid abnormality between the $\mathrm{CKD}$ and control group

\begin{tabular}{llll}
\hline LIPID ABNOR- & CKD group & $\begin{array}{l}\text { Control group } \\
\mathrm{n}(\%)\end{array}$ & P value \\
MALITY & $\mathrm{n}(\%)$ & $31(29.5)$ & 1.000 \\
\hline Elevated TC & $31(29.5)$ & $14(13.3)$ & 0.261 \\
Elevated TG & $20(19.0)$ & $16(15.2)$ & 0.850 \\
Elevated LDL-C & $17(16.2)$ & $8(7.6)$ & $<0.001$ \\
Reduced HDL-C & $32(30.5)$ & $25(33.8)$ & $<0.001$ \\
High AIP & $68(64.8)$ & $41(39.0)$ & 0.002 \\
Dyslipidaemia & $63(60.0)$ & & \\
\hline
\end{tabular}

The prevalence of elevated serum TG, reduced serum HDL-C and high AIP increased significantly across CKD stages 1 to 5 with $\mathrm{p}$ values of $0.02,0.04$ and 0.03 respectively. 


\section{Original Article}

There was no significant increase in prevalence of ele- daemia across the CKD stages.(Table 4) vated serum TC, elevated serum LDL-C and dyslipi-

Table 4 Prevalence of Lipid abnormalities across the CKD stages

\begin{tabular}{lllllll}
\hline Parameter & $\begin{array}{l}\text { CKD stage 1 } \\
\mathrm{n}(\%)\end{array}$ & $\begin{array}{l}\text { CKD stage } \\
\mathrm{n}(\%)\end{array}$ & $\begin{array}{l}\text { CKD stage 3 } \\
\mathrm{n}(\%)\end{array}$ & $\begin{array}{c}\text { CKD stage 4 } \\
\mathrm{n}(\%)\end{array}$ & $\begin{array}{c}\text { CKD stage 5 } \\
\mathrm{n}(\%)\end{array}$ & P value \\
\hline Elevated TC & $3(42.9 \%)$ & $9(40.9 \%)$ & $10(21.7 \%)$ & $7(26.9 \%)$ & $2(50 \%)$ & 0.37 \\
Elevated TG & $0(0 \%)$ & $3(13.6 \%)$ & $8(17.4 \%)$ & $4(26.9 \%)$ & $2(50 \%)$ & 0.02 \\
Elevated LDL-C & $2(28.6 \%)$ & $3(13.6 \%)$ & $6(13 \%)$ & $5(19.2 \%)$ & $1(25 \%)$ & 0.82 \\
Reduced HDL-C & $2(28.6 \%)$ & $2(9.1 \%)$ & $16(34.8 \%)$ & $10(38.5 \%)$ & $2(50 \%)$ & 0.04 \\
High AI & $3(42.9 \%)$ & $12(54.5 \%)$ & $30(65.2 \%)$ & $20(76.9 \%)$ & $3(75 \%)$ & 0.03 \\
Dyslipidaemia & $5(71.4 \%)$ & $12(54.5 \%)$ & $27(58.7 \%)$ & $15(57.7 \%)$ & $4(100 \%)$ & 0.72 \\
\hline
\end{tabular}

Table 5 Association between dyslipidaemia, gender, age and obesity among CKD subjects

\begin{tabular}{llll}
\hline Parameter & $\begin{array}{l}\text { Dyslipidaemia } \\
\text { Present } \\
\mathbf{n}(\%)\end{array}$ & $\begin{array}{l}\text { Dyslipidaemia } \\
\text { Absent } \\
\mathbf{n}(\%)\end{array}$ & P value \\
\hline Male & $34(51.5)$ & $32(48.5)$ & 0.02 \\
Female & $29(74.4)$ & $10(25.6)$ & \\
$<45$ years & $19(40.4)$ & $28(59.6)$ & 0.94 \\
$\geq 45 y e a r s$ & $35(60.3)$ & $23(39.7)$ & \\
Non-obese & $57(61.3)$ & $36(38.7)$ & 0.45 \\
Obese & $6(50.0)$ & $6(50.0)$ & \\
\hline
\end{tabular}

The prevalence of dyslipidaemia was $74.4 \%$ in female CKD patients and this was significantly higher than $51.5 \%$ present in male CKD patients $(\mathrm{p}=0.02)$. Dyslipidaemia was commoner in CKD patients who were 45 years and above although this was not statistically significant ( $\mathrm{p}=0.94)$. There was also no significant association between obesity and dyslipidaemia in the CKD patients. (Table 5)

\section{DISCUSSION}

The mean age of the CKD patients was $46.98 \pm 16.81$ years which is similar to previous reports in Nigeria. 5,24 This buttresses the fact that CKD affects the economically productive age group in Nigeria. Majority of the CKD patients were in stages 3 and 4 and this may be explained by poor health seeking habits and late presentation of Nigerians patients.

The median serum TG, LDL-C were significantly higher while mean serum HDL-C was lower in the CKD group compared to the control in this study. This pattern of dyslipidaemia is similar to reports from previous studies from other parts of Nigeria.,

There was no significant difference between mean serum TC in both groups which is also similar to the reports by Agaba et al. ${ }^{25}$
The overall prevalence of dyslipidaemia in the CKD patients in this study was $60 \%$ and was commoner in those who were 45 years and above. Earlier studies on lipid profile of adult Nigerian CKD patients assessed prevalence of individual lipid abnormality, but not overall prevalence of dyslipidaemia in the studied population. ${ }^{5-7}$ This prevalence is however high compared to the overall prevalence of $45 \%$ reported in a paediatric CKD population. ${ }^{28}$ The lower prevalence in the latter study may be explained by the conservative cut off used in the definition of dyslipidaemia and also by the fact that it was conducted in a paediatric age group.

Dyslipidaemia was significantly higher in female CKD patients compared to the male subjects. The higher prevalence of dyslipidaemia in female CKD patients may be explained by the higher cut off of less than $50 \mathrm{mg} / \mathrm{dl}$ used to diagnosed low HDL compared to a lower value of less than $40 \mathrm{mg} / \mathrm{dl}$ used in males. Also, oestrogen which is known to be protective against dyslipidaemia by increasing the levels of HDL-C in premenopausal females is usually low in females CKD patients. $^{29}$

There was association between dyslipidaemia and severity of CKD unlike previous reports. ${ }^{6,7}$ This study showed significant increase in the prevalence of reduced HDL-C and elevated TG with worsening GFR, hence early evaluation and management of dyslipidaemia should be advocated in these patients in order to retard progression of CKD to ESRD and prevent development of cardiovascular disease.

The AIP has been reported to have higher sensitivity compared to other ratios in predicting cardiovascular events in patients. ${ }^{30}$

It is the best determinant of fractional esterification rate of HDL-C and thus, a better predictor of cardiovascular risk than previously used lipid parameters. ${ }^{31}$ The prevalence of CKD patients with high AIP was $64.8 \%$ and this was significantly higher than $33.8 \%$ found in the control group. 
This is the first study (to the best of our knowledge) that assessed AIP across CKD stages in Nigeria. There was also significant increase in AIP in the CKD patients with worsening renal function. It could also be inferred that that there is increasing susceptibility of CKD patients to myocardial infarction with worsening renal function since AIP strongly predicts myocardial infarction. ${ }^{32}$ The prevalence of high AIP was higher than the individual lipid abnormality or overall dyslipidaemia. This underscores the need to evaluate CKD patients for atherogenic risk by using ratios from the different lipid components instead of considering each component in isolation.

The use of statins has been found to reduce cardiovascular risk and retards CKD progression. ${ }^{13,33}$ Schieffer et al also reported that weight reduction significantly reduce atherogenic risk factors such as blood pressure and various lipid components, ${ }^{34}$ hence regular exercise and lifestyle modification aimed at weight loss will also complement the effect of lipid lowering medications.

In conclusion, dyslipidaemia is a common cardiovascular risk factor in CKD especially in females and older CKD patients. Some lipid abnormalities such as reduced HDL-C, elevated TG and atherogenic risk tend to increase with worsening renal function.

We recommend early evaluation of CKD patients for dyslipidaemia and cardiovascular risk using ratio of lipid components at all stages with the aim of management with both lifestyle modification and therapeutic intervention

\section{ACKNOWLEDGEMENT}

We appreciate the contributions of resident doctors of department of internal medicine and renal nurses of University of Benin Teaching Hospital, Benin, Edo State, Nigeria towards the completion of this study.

\section{REFERENCES}

1. Rayner HC, Pisoni RL, Bommer J, Canaud B, Hecking E, Locatelli F et al. Mortality and Hospitalization in haemodialysis in five European countries. Results from dialysis outcome and practice patterns study (DOPPS). Nephrol Dial Transplant 2004; 19:108-120.

2. Foley RN, Parfrey PS, Sarnak MJ. Clinical and echocardiographic disease in patients starting end stage renal disease therapy. Kidney Int 1995; 47(1):186-192

3. Yusuf S, Hawken S, Ounpuu S, Dans T, Avezum A, Lanas F, et al. INTERHEART Study Investigators. Effect of potentially modifiable risk factors as- sociated with MI in 52 countries (The INTERHEART Study): case-control study Lancet 2004;364(9438):937-952

4. Locatelli F, Pozzoni Pietro, Tentori F, Vecchio LD. Epidemiology of cardiovascular risk in patients with chronic kidney disease. Nephrol Dial Transplant $2003 ; 18(7): 2-9$

5. Akpan EE, Ekrikpo UE, Effa EE, Udo AA, Kadiri S. Assessment of dyslipidemia in pre-dialysis patients in south-west Nigeria. Niger Med $J$ 2014;55(3):214-9

6. Chijioke A, Makusidi AM, Shittu OA, Sanni MA, Biliaminu SA, Abdul-Rahman S et al. Pattern of lipid profile in dialysis naïve patients from Ilorin, Nigeria. Internet J Nephrol 2011; 6(1):1-7.

7. Mshelia DS, Brutai LB, Mamza YP. Lipid profile in predialysis patients chronic kidney disease patients attending University of Maiduguri Teaching Hospital, Nigeria. Niger J Clin Pract 2002; 12(2):173-178.

8. Chen SC, Hung CC, Kuo MC, Lee JJ, Chiu YW, Chang $\mathrm{J}$ et al. Association of Dyslipidemia with Renal Outcomes in Chronic Kidney Disease. PLoS ONE $2013 \quad$ 8(2): $\quad$ e55643 doi:10.1371/journal.pone. 0055643

9. Fried LF, Orchard TJ, Kasiske BL. Effect of lipid reduction on the progression of renal disease: A meta-analysis. Kidney Int 2001;59:260-269

10. Schlondorff D. Cellular mechanisms of lipid injury in the glomerulus. Am J Kidney Dis. 1993;22(1):7282

11. Guijario C, Kasiske BL, Kuin Y, O'Donnell MP, Lee HS, Keane WF. Early glomerular changes in rats with dietary-induced hypercholesterolemia. $\mathrm{Am}$ J Kidney Dis 1995;26(1):152-161.

12. Muntner P, He J, Astor BC, Folsom AR, Coresh J. Traditional and nontraditional risk factors predict coronary heart disease in chronic kidney disease: Results from the Atherosclerosis Risk in Communities Study. J Am Soc Nephrol 2005;16(2):529-538

13. Atthobari J, Brantsma AH, Gansevoort RT, Visser ST, Asselbergs FW, van Gilst WH. The effect of statins on urinary albumin excretion and glomerular filtration rate: Results from both a randomized clinical trial and an observational cohort study. Nephrol Dial Transplant 2006;21(11): 3106-3114.

14. Fleiss JL. Statistical methods for rates and proportions. $2^{\text {nd }}$ ed. New York, NY: John Wiley\& Sons; 1981

15. Okaka EI, Eiya BO. Prevalence and pattern of dyslipidaemia in a rural community in southern Nigeria. Afr J Med Health Sci 2013;12:82-86

16. Timothy P, Catherine JA, Lawrence LR. Enzymatic determination of triglycerides free cholesterol and 
total cholesterol in tissue lipid extracts. Clinical $B i$ ochemistry 1993;26(1):36-42

17. Ononogbu IC, Lewis B. Lipoprotein fractionation by a precipitation method; a simple quantitative procedure. Clinica Chemica Acta 1996; 71(3):397402

18. Naoto F, Kazuhhio H, Noriaki W, Koari K, Asako $\mathrm{S}$, Hikari $\mathrm{O}$ et al. Validation of Friedewald equation for evaluation of plasma LDL-cholesterol. J Clin Biochem Nutri 2008; 43(1):1-5

19. Abefe SA, Abiola AF, Olubunmi AA, Adewale A. Utility of predicted creatinine clearance using MDRD formula compared with other predictive formulas in Nigerian patients. Saudi J Kidney Dis Transpl 2009; 20(1):86-90.

20. Clinical guidelines on the identification, evaluation and treatment of overweight and obesity in adults The evidence report. National Institutes of Health. Obes Res 1998;6 (Suppl 2):51 -209

21. KDIGO 2012 Clinical Practice Guideline of evaluation and management of CKD. Kidney Int Suppl 2013;3(1):1-150.

22. Executive summary of the third report of the National Cholesterol Education Program (NCEP) Expert Panel on Detection, Evaluation and Treatment of High Blood Cholesterol in Adults (Adult Treatment Panel III). JAMA 2001;285(19):2486.

23. Dobiasova M. AIP- atherogenic index of plasma as a significant predictor of cardiovascular risk: from research to practice. Vnitr Lek. 2006;52(1):64-71

24. UlasilI, Ijoma CK.The enormity of chronic kidney disease in Nigeria.The situation in a teaching hospital in Southeast Nigeria. J Trop Med Volume 2010(2010), Article ID 501957, http.//dx.doi.org/10.1155/2010/501957 accessed on the $3^{\text {rd }}$ October, 2015

25. Agaba EI, Agabaji OO, Anteyi EA, Omodu PO, MshelIa RS. Serum lipid in pre-dialysis chronic re- nal failure patients in Jos University teaching hospital. Highland Med Res J 2003;1(3):13-17

26. Baragetti A, Norata GD, Sarcina C, Rastelli F, Griore L, Garlaschelli K. High density cholesterol levels are independent predictors of progression of chronic kidney disease. $J$ Intern Med 2013;274(3):252-262

27. Mulec H, Johnson SA, Bjoruk S. Relation between serum cholesterol and diabetic nephropathy. Lancet 1990;335(8704):1537-1538

28. Saland JM, Pierce LB, Furth SL. Dyslipidaemia in children with chronic kidney disease: A report of chronic kidney disease in children. Kidney Int 2010;78(11):1154-1163

29. Khalifa M. The biochemical changes of some female sex hormones in end stage renal diseases (ESRD) $J$ Nephrol Therapeut 2012:2(5): DOI:10.4172/2161-0959.1000e108

30. Dobiasova M. AIP--atherogenic index of plasma as a significant predictor of cardiovascular risk: from research to practice. Vnitr Lek 2006 ;52(1):64-71

31. Dobiasova M, Frohlich J. The plasma parameter $\log (\mathrm{TG} / \mathrm{HDL}-\mathrm{C})$ as an atherogenic index: correlation with lipoprotein particle size and esterification rate in apo B- lipoprotein- depleted plasma.(FERHDL). Clin Biochem. 2001;34(7):583-588

32. Lafta MA. A Comparative Study for Some Atherogenic Indices in Sera of Myocardial infarction, Ischemic Heart Disease Patients and Control. J Nat Sci Res 2014; 4(8) :96-102

33. Hou W, Lv J, Perkovic Y, Yang L, Zhao N , Jardine MJ et al. Effects of statin therapy on cardiovascular and renal outcomes in patients with chronic kidney disease: a systematic review and met-analysis. Eur Heart J 2013;34(24):1807-1817

34. Schieffer B, Moore D, Funke E, Hogan S, Alphin $\mathrm{F}$, Hamilton $\mathrm{M}$ et al. Reduction of atherogenic risk factors by short term weight reduction. Klinische Wochenschrift 1991;69(4):163-16 